\title{
A DeCadênCIA da ExistêNCIA: Notas Sobre a Mobilidade da Vida
}

Thiago Aquino ${ }^{I}$

\begin{abstract}
RESUMO: Este artigo tem como temática central o conceito de movimento, visando a examinar a pertinência do alargamento da sua aplicação na descriçấo fenomenológica da existência humana. Pretendo oferecer uma interpretação possível para a afirmação feita por Heidegger, em Ser e Tempo, de que o fenômeno existencial da decadência [Verfallen] é um conceito ontológico de mobilidade existencial.
\end{abstract}

PALAVRAS-CHAVE: Heidegger. Movimento. Privação. Ontologia. Si-mesmo.

À primeira vista, Heidegger não seria considerado interlocutor privilegiado para a discussão do fenômeno do movimento. É fácil constatar que esse conceito não possui centralidade no conjunto da terminologia da fenomenologia hermenêutica. Além disso, a dimensão histórica do projeto da ontologia fundamental apresentado em Ser e Tempo fortaleceu, pelo menos no início da sua formulação, um diálogo muito mais detido com as ciências humanas do que com as ciências da natureza, as quais elaboram mais frequentemente a explicação teórica do fenômeno do movimento. Apesar dessas impressóes, uma segunda leitura, mais cuidadosa, dos textos revela que há uma presença, mesmo sub-reptícia, da temática do movimento no horizonte da análise ontológico-existencial. A intenção deste artigo é ressaltar a relevância desse fenômeno na caracterização do ser-aí.

É possível identificar ao menos duas direçôes em que o problema do movimento é abordado no pensamento de Heidegger: i) em primeiro lugar, o fenômeno do movimento é visualizado na sua máxima universalidade enquanto questáo ontológica que abrange a totalidade do ente: em que medida o movimento é uma determinação do ser em geral? Em outras palavras, o movimento pertence ao ser ou, ao contrário, é seu mais claro contraponto?; ii) em segundo lugar, o movimento é discutido no interior da interrogação

\footnotetext{
${ }^{1}$ Professor no Departamento de Filosofia da Universidade Federal de Pernambuco (UFPE). E-mail: tama_aquino@hotmail.com
} 
ontológico-existencial desenvolvida pela analítica existencial, a qual consiste, precisamente, na investigação das condiçóes de possibilidade da compreensão de ser. É no contexto dessa descrição do ser humano, motivada pela busca de um solo para a questão do ser, que Heidegger questiona se e como o movimento pertence constitutivamente à vida fática. Nessa perspectiva, a interrogação principal seria: o que significa dizer que há uma mobilidade específica da existência? Trata-se de saber, se seria possível, com base nessa análise existencial, tomar o movimento como referência para caracterizar os diferentes comportamentos do ser-aí. Veremos que a atividade filosófica, redefinida como exercício "violento" de interrogação, contraposto à tendência decadente inicial da existência cotidiana, pode ser uma clara ilustração da aplicação do conceito mencionado. Temos, entáo, uma sequência de problematizaçáo que aborda o fenômeno do movimento, respectivamente, numa perspectiva ontológica, ontológico-existencial e ôntico-existenciária. Em correspondência aos diferentes caminhos de análise indicados, este artigo está estruturado em duas partes principais: 1 . No primeiro momento, examino o fenômeno do movimento enquanto problema ontológico geral, acompanhando, embora de modo breve, o diálogo de Heidegger com Aristóteles; 2. No segundo passo, apresento uma interpretaçáo do existencial da decadência, com o propósito de esclarecer em que medida a mobilidade é uma determinação ontológica do existir humano.

No cerne, as considerações adiante visam apenas a oferecer uma interpretação para afirmação, encontrada em Ser e Tempo, de que a existência possui uma mobilidade própria expressa no existencial da decadência [Verfallen]. De fato, no fim do $\$ 38$, encontramos a observação de que "[...] a decadência é um conceito ontológico de movimento” (HEIDEGGER, 2001, p. 180). Visto que esse conceito não recebe nenhum esclarecimento na analítica existencial, a tese mencionada desperta alguns questionamentos imediatos: em que medida podemos realmente descrever a existência como móvel? Qual o significado desse conceito, nesse contexto? Trata-se de uma linguagem figurada, ou seja, de uma metáfora, ou será que podemos encontrar, efetivamente, na estrutura ontológica do ser-aí, indícios de uma forma própria de movimentação? A pretensão deste artigo consiste principalmente em avançar uma proposta de interpretação dessa afirmação sobre a mobilidade da decadência e, secundariamente, apontar para o problema filosófico fundamental a partir do qual a mobilidade da existência poderá ser tematizada. 


\section{MOVIMENTO ENQUANTO PROBLEMA ONTOLÓGICO GERAL}

A primeira direçáo de abordagem do fenômeno do movimento é a mais ampla, porque o interroga enquanto possível determinação do ser em geral. Tal interrogação é aquela que, certamente, encontrará na obra de Heidegger a menor contribuição. Isso se deve à inexistência, na fenomenologia hermenêutica, de uma concepção ontológica suficientemente abrangente para tematizar o movimento como uma determinação do ser enquanto tal. Respeitando a ordem das fundamentaçôes, não podemos saber se há uma correlação originária entre ser e movimento, sem antes conquistar um solo adequado para a problemática ontológica em geral. Apenas quando estiver determinado o sentido do ser em geral e a amplitude da compreensão de ser, "[...] só então, será possível também diferenciar o que pertence a uma ciência do ser enquanto tal, suas possibilidades e derivaçóes" (HEIDEGGER, 2001, \$44, p. 230). A repetição da questão do sentido do ser em geral é a meta contínua do pensamento de Heidegger, em relação à qual todas as outras análises e meditações assumem caráter preparatório; inclusive o projeto da ontologia fundamental o qual prepara o solo para essa questão, com a investigação de um possível nexo entre compreensão de ser e o horizonte transcendental do tempo. Tendo em vista que esse projeto não foi concluído por causa do impasse no qual desemboca Ser e Tempo, não há base suficiente para desdobrar concretamente uma interrogação ontológica abrangente sobre o movimento.

Não havendo uma resposta direta na fenomenologia hermenêutica à pergunta sobre a natureza da relação entre ser e movimento, somos obrigados a fazer um "desvio" através das apropriaçóes hermenêuticas da história da filosofia, não com a intenção de atribuir a Heidegger a resposta a um problema, que ele não propôs, mas para recuperar elementos do fenômeno do movimento, visualizado por meio de interpretaçóes fenomenológicas as quais reverberam na sua obra. Sabe-se hoje que o projeto da ontologia fundamental, concebido sob a forma de uma analítica existencial, é o resultado de um diálogo atencioso com a experiência histórica da existência aberta pelo cristianismo, mais especificamente através da confrontação hermenêutica com os textos de Paulo, Agostinho e Lutero, bem como da leitura crítica da obra de Aristóteles, especialmente aspectos da física, da ética e da metafísica. Essas referências configuram os pressupostos principais da "[...] interpretação da vida greco-cristâ" (HEIDEGGER, 2005b, p. 369) que, de acordo com Heidegger, sustenta toda antropologia filosófica do ocidente, permeando, ainda que sorrateiramente, todas as discussóes filosóficas em torno da "natureza 
humana”. A predominância dessa interpretação indica a permanência de certas noçóes e conceitos ainda não suficientemente pensados em sua proveniência. A motivação básica do retorno interpretativo às fontes é recuperar, pela interpretação fenomenológica, as experiências originárias situadas na base da formulação dos conceitos fundamentais da história da filosofia, especialmente em função da necessidade de esclarecer a questão central relativa ao fenômeno da vida fática.

Sem reduzir o mais importante ao mero cálculo histórico de influências, pode-se constatar que a configuração conceitual e temática da analítica existencial foi elaborada, em grande parte, pela leitura de Aristóteles. No texto intitulado Interpretaçóes Fenomenológicas sobre Aristóteles (1922), enviado por Heidegger a Paul Natorp, para pleitear uma vaga em Marburgo, Aristóteles é descrito como ápice da filosofia grega e tomado como referência básica de toda a filosofia posterior, constituindo, assim, um ponto de inflexão privilegiado para a apropriação crítica da história da filosofia. Parece-me que a centralidade da filosofia aristotélica na elaboração da analítica existencial pode ser confirmada através do exame do fenômeno do movimento, sobretudo na tentativa de conceber um modo de movimento próprio da existência humana. De fato, o que permite avançar a tese fenomenológica da mobilidade da existência na analítica existencial é a manutenção de certos aspectos do fenômeno do movimento que sobressaem na interpretação fenomenológica da física aristotélica. Sem comprometer-se completamente com a concepção aristotélica de movimento, Heidegger transpóe e retraduz, resguardando as diferenças principais, a sua estrutura básica para a analítica existencial.

Para Heidegger, o fenômeno do movimento não deve ser considerado apenas uma dificuldade particular das investigaçóes físicas, mas um tema ontológico que perpassa a totalidade do filosofar do estagirita. A dimensão ontológica do fenômeno do movimento é originada pela posição negativa desenvolvida pelos Eleatas, que separam radicalmente o ser do devir, exigindo de Platão e Aristóteles uma rearticulação entre esses fenômenos. Daí surge a abrangência da interrogação proposta por Aristóteles: qual a natureza da relação entre ser e movimento? Em que medida o movimento é uma determinação do ser? Como apreender o ser-em-movimento como caráter ontológico do ente natural? De acordo com Heidegger, Aristóteles teria alcançado um patamar de interrogação que não permite mais considerar o movimento como uma questão qualquer entre outras, porque propóe uma interrogação na qual o “[...] ser-movido [Bewegtsein] é questionado e apreendido explicitamente 
como o modo fundamental do ser" (HEIDEGGER, 2004a, p. 244). Ainda que a referência para a discussão sejam as coisas naturais, de algum modo, a natureza determina-se como ponto de partida inevitável de toda interrogaçáo ontológica, porque a filosofia primeira será delimitada por contraste com a física (Met. VI, 1, 1026a , 21-35). Essa correlação é o que, possivelmente leva Heidegger a afirmar que "[...] a 'Física' aristotélica é o livro fundamental encoberto da filosofia ocidental e, por isso, nunca suficientemente pensado" (HEIDEGGER, 2004a, p. 242). Trata-se do livro fundamental, porque a relação estabelecida ali entre ser e movimento reverbera de diversos modos em outros campos investigativos. Como observa Heidegger, no denominado relatório Natorp:

Aristóteles conquista com sua "física" um novo ponto de partida fundamental desde onde germinam sua ontologia e lógica e que, a partir de então, passará a dominar a história da antropologia filosófica, apresentada anteriormente de modo esquemático e retrospectivo. O fenômeno central, cuja explicaçáo constitui o tema da física, é o ente no como do seu sermovido. (HEIDEGGER, 2005b, p. 371). ${ }^{2}$

A teoria aristotélica do movimento [kinesis] é desenvolvida nos três primeiros capítulos do livro III da Física. No primeiro capítulo, Aristóteles define o movimento como "[...] a atualidade [enteléquia] do que é em potência enquanto tal" (Fis. III, 1, 201 a 11 ). Dizer que o movimento é o ato de uma potência implica descrevê-lo como uma passagem, ou seja, que o movimento náo pode ser localizado nem no início e nem no fim pensados estaticamente, mas no processo intermediário que configura um estar-a-caminho. A transição indica que todo movimento [kinesis] é mudança [metábole], uma transformação de algo em algo. De acordo com Aristóteles, no livro VII (Zeta) da Metafísica, todo movimento inclui algo do qual deriva, algo por obra do qual deriva e algo para o qual tende (Met. Z, 7, 1031 b 12-15). A concepção de passagem corresponde a uma dificuldade particular, porque as duas opçóes iniciais para o ponto de início do movimento parecem inadequadas. Como ressalta Aristóteles,

[...] a razão pela qual o movimento parece indeterminado consiste em que ele não é redutível nem só à potência nem só ao ato. De fato, não se move necessariamente nem a quantidade em potência, nem a quantidade

\footnotetext{
${ }^{2}$ Posteriormente, Heidegger irá destacar a análise dos fenômenos do acaso [tychê] e espontâneo [automaton] como decisivos para a elaboração ontológica da mobilidade "histórica» da vida fática. Cf. p. 395. Salvo indicação contrária todas as traduções são de minha autoria.
} 
em ato; o movimento é, evidentemente, um ato, mas um ato incompleto: e justamente por isso é difícil compreender o que seja movimento. (Met. K, 9, 1066a 18-21).

A dificuldade da transição é clara. O que já é, em ato, é o que é e, portanto, não necessita tornar-se nada, não entra em movimento; o que está em potência também não devém, porque nada é. Este era, justamente, o argumento apresentado por Parmênides para rejeitar o devir como irrelevante, do ponto de vista ontológico.

Para Aristóteles, a oposição parmenideana entre ser e não-ser pode ser eliminada, se o movimento for concebido como um ato incompleto [energeia ateles]. Se é apenas enquanto transição entre a potência e o ato, então o movimento consiste no processo intermediário no qual a potência de um ato se atualiza. Em outras palavras, o movimento é um ato [energeia], mas ainda inacabado. A incompletude do movimento é determinada pelo seu ponto de chegada, pois todo movimento tem um fim, para o qual tende e que, uma vez alcançado, configura seu termo. O conceito de telos, utilizado por Aristóteles para descrever a direçáo do movimento, admite, ao menos, três acepçóes: meta (escopo, alvo), término de um processo e acabamento. A primeira acepção tem sua aplicação mais apropriada no domínio da ação, porque, no caso do ente natural, incapaz de deliberação, o telos deve ser concebido como uma espécie de termo extremo no qual o movimento se torna completo, acabado, pleno no sentido de perfeição [teleios]. Para Aristóteles, o movimento está baseado numa causalidade teleológica, ou seja, é um processo já "pré-determinado" pelo seu termo. A transição gradual da potência para o ato configura um alcançar um acabamento, um ter em posse seu próprio termo.

A perfeição do acabamento da energeia lhe concede um primado na determinação do ser, interpretado como presentar-se, sobre a potência, interpretada como aptidão. $\mathrm{O}$ eidos, forma ou aspecto, determina o ponto de chegada e, simultaneamente, o ponto de partida, articulando assim todo o processo de transição. Como observa Heidegger, no texto A Essência e o Conceito de Physis em Aristóteles, a "[...] energeia preenche a essência do presentar-se puro originariamente, na medida em que significa o ter-seem-obra-e-no-fim, aquilo que deixou para trás todo 'ainda não' da aptidão para..., ou melhor, já trouxe junto e para diante no preenchimento do aspecto consumado" (HEIDEGGER, 2004a, p. 299). Sendo o movimento um processo de passagem, não importa somente determiná-lo pela conclusão 
do telos, entendido enquanto acabamento da entelequia, porém, também pelo começo que será considerado à luz do término do processo. Enquanto atualização de uma potência que ainda está em curso, o movimento é um ato incompleto que ainda não alcançou seu acabamento, porque parte de uma carência, uma falta, um tipo qualquer de não-ser. Esta "negatividade" inerente ao devir favorecia a crítica eleata, porque aparenta assumir o inaceitável: a afirmação do não-ser. Para escapar da dificuldade apontada, Aristóteles observa, no capítulo 8 do livro I da Física, sua convergência, nesse ponto, com adversários da noção de movimento:

[...] nós estamos em acordo com eles em sustentar que nada pode advir em sentido absoluto do que não é, porém defendemos que algo pode provir do que não é em sentido relativo, por acidente. Pois uma coisa torna-se a partir da privação, que por sua natureza não é, náo de um constituinte seu. (Física, I, 8, 191a 13-16).

A noção de privação [steresis $]^{3}$ pode contribuir para a dissolução da aporia do movimento, justamente porque é um modo não-absoluto de não-ser. É somente quando considerado desde a perspectiva do término do movimento que o ponto de partida pode ser apreendido como um "não- ser ainda" negativo, ou seja, como a privação de algo. A ausência ou falta sempre será determinada através da relação com o telos. A privação constitui um intrincado problema para a ontologia, já que exprime uma ausência que não pode ser concebida como a mera negação da presença, mas somente como ausência que se anuncia na presença. Heidegger comenta:

[...] quando algo falta, entáo o que está faltando se foi, mas neste próprio 'se foi' a falta mesma nos incomoda e inquieta porque tudo o que 'falta' só pode fazer falta se ele mesmo está 'aí, isto é, é ou constitui um ser. Steresis enquanto ausência não é apenas ausência, mas um presentar-se [Anwesung], a saber, aquela presença na qual se presenta justamente o ausentar-se- e não, por exemplo, o que está ausente. (HEIDEGGER, 2004a, p. 297).

Podemos exemplificar essas relaçóes por intermédio do processo de convalescência, ou seja, o movimento qualitativo no decorrer do qual um corpo doente recupera a saúde. Visualizada desde a perspectiva do termo do

\footnotetext{
${ }^{3}$ Trata-se de um termo com múltiplas acepçōes (cf. Met, V, 22), podendo-se destacar duas significaçốes principais do ser subtraído que caracteriza a privação: 1. simples falta ou ausência (ex: não ter olhos), b. não ter ou possuir o que por natureza se devia ter (ex: cegueira).
} 
movimento, a doença evidencia-se como a privação da saúde, ou seja, uma falta que é capaz de apontar para o que está faltando unicamente porque se mostra em si mesma como ausência.

Resulta desta brevíssima análise da concepção aristotélica que o movimento [kinesis] é um processo de transição, de passagem ou virada [metábole] constituído por três momentos: i) um ponto de partida, desde onde o movimento se inicia e que não é descrito de modo neutro, mas apreendido como a privação do ainda-não-ser; ii) um ponto de chegada, em direção do qual o movimento se desdobra, configurando o seu termo, seu término; e iii) um substrato, no qual a transição ocorre. É importante enfatizar que o arcabouço conceitual aqui elaborado não foi conquistado por Aristóteles, tendo em vista uma descrição da existência humana. De fato, o horizonte de tematização do movimento é determinado pela investigação dos princípios e causas do ente natural na física, bem como pela pergunta geral sobre o movimento enquanto determinação do ser. O fenômeno do movimento é apreendido através de conceitos como energeia-dunamis, articulado de acordo com o esquema das categorias, localizado nas investigaçóes físicas, por isso, não se pode transcrever, sem maiores reconsideraçóes, as características do movimento ressaltadas acima para esclarecer a mobilidade própria da vida fática. Feita a ressalva, ainda assim, é possível constatar implicitamente na analítica existencial alguns elementos da estrutura básica do movimento tal como é exposta por Aristóteles. Essa constatação justifica a necessidade de um aprofundamento do fenômeno do movimento para incluir nele a especificidade da existência fática. De que modo acontece essa passagem? De que modo poderíamos dar sentido ao uso do conceito de movimento para descrever o existir humano?

\section{Decadência ou a mobilidade enquanto determinaçáo ontológica da EXISTÊNCIA}

A mobilidade da existência não é o movimento do subsistente. ${ }^{4}$

De início, parece pouco problemático aplicar à existência humana o conceito de movimento, porque, de algum modo, evidencia-se fenomenalmente para nós o caráter radicalmente contingente, mutável e multifacetado da

${ }^{4}$ HEIDEGGER. Sein und Zeit, 2001, $\$ 72$, p. 374-5: "Die Bewegtheit der Existenz ist nicht die Bewegung eines Vorhandenen.” 
vida fática e das circunstâncias nas quais está inserida. Nos termos de uma experiência imediata, não há como negar a "dinamicidade" da vida. De fato, fazemos diversos usos dessa noção na descrição do ser humano. Podemos, por exemplo, perguntar: o que fazer com a inquietação que nos acomete diante da apatia política, diante do repousar alienado frente às mercadorias e à ilusão do espetáculo? Pode-se falar da necessidade de quebrar com esse repouso, através da movimentação política. Fala-se também na história da filosofia a respeito de movimentos filosóficos. E é claro que poderíamos nos estender indefinidamente nas exemplificaçôes do caráter móbil da existência, pois não é aqui onde está localizada a dificuldade, mas na falta de clareza filosófica dessa constatação inicial, visto que permanecemos sem saber muito bem em que sentido podemos dizer que estamos em movimento. Em que medida o movimento caracteriza a existência? Será que esses usos são metafóricos, figuras de linguagem, meras imagens, ou será que a existência é constituída ontologicamente para poder oscilar entre esses extremos da inaçáo e da açáo, da mobilização e do repouso, da inquietude e da serenidade, da apropriaçáo ou perda de si?

O maior desafio não consiste na apresentação de exemplificaçôes para o que chamamos vagamente de "dinamicidade" da vida, mas em encontrar uma possibilidade de conceituaçáo filosófica que não desconsidere a especificidade ontológica do ser humano. Quando transposto para o contexto da problemática ontológico-existencial, o conceito de movimento necessita ser repensado, uma vez que suas características fundamentais são determinadas usualmente, tomando como referência entes diferentes da existência humana. Heidegger tem clareza das dificuldades que a linguagem impóe às pretensóes de significar o ser, de descrevê-lo em toda sua riqueza fenomenal. A principal tarefa que se impóe para o discurso filosófico, o qual pretende manter a intuição aristotélica de que o "ser é dito de muitos modos", é o de resguardar a pluralidade ontológica através da criação de conceitos a partir da atenção às especificidades fenomenais, evitando todo e qualquer "esquema geral" de descrição. Justamente em função da exigência de resguardar a multiplicidade ontológica que a mobilidade da existência é circunscrita na analítica existencial por meio das relaçôes entre uma privação e um "fim", porém, modificados ou redefinidos em funçáo da constituição ontológica do ser-aí. Somente a recuperação e a reinterpretação desses conceitos, na estrutura argumentativa da analítica existencial, podem dar um sentido ao uso da noção de movimento para a descrição fenomenológica da existência. 
Para satisfazer a exigência fenomenológica e possibilitar a separação temática do ser-em-movimento dos outros entes e da existência histórica, Heidegger propõe a diferenciação terminológica entre as noçôes de movimento [Bewegung] e mobilidade [Bewegtheit], reservando este último termo para designar a mobilidade da vida fática na analítica existencial. Esta é uma distinção estabelecida no texto Investigaçóes Fenomenológicas da Aristóteles (1922) e mantida até pelo menos Ser e Tempo, onde Heidegger ressalta, no $\$ 72$, que

[...] o esclarecimento ontológico do 'nexo vital' [Lebenszusammenhang], quer dizer, da específica extensão, mobilidade [Bewegtheit] e persistência do ser-aí deve ser posto no horizonte da constituiçáo temporal deste ente. A mobilidade [Bewegtheit] da existência não é o movimento [Bewegung] de um subsistente. (HEIDEGGER, 2001, p. 374-375).

Desse trecho podemos extrair duas indicaçóes importantes para análise. Em primeiro lugar, a indicação de que o fenômeno da mobilidade da vida fática está conectado com o problema da ipseidade. Em segundo lugar, que a mobilidade da vida fática deve ser diferenciada do movimento dos entes subsistentes, ou seja, não pode ser concebida como um processo observável e explicável teoricamente a partir de relaçóes causais. A mobilidade da vida fática caracteriza-se por ser, não um acontecimento no qual estamos envolvidos, mas um acontecer que nós mesmos somos. O que está em questão nas movimentaçôes existenciais é o significado da ipseidade, da "mesmidade" do si-mesmo.

Em Ser e Tempo, a ipseidade é concebida existencialmente. $\mathrm{O}$ eu não é um dado persistente a ser encontrado no fluxo subjetivo das vivências pela reflexão fenomenológica ou introspecção psicológica, porém, um exercício de existir apenas acessível a si mesmo no seu próprio perfazimento. A existência relaciona-se consigo mesma compreensivamente, projetando-se para possibilidades de ser-no-mundo, por isso, somente descerra a si mesma com base nas possibilidades que assume. Todas as características ontológicas desse ente são modos de ser assumidos pela própria existência.

Sendo assim, de que modo aparece o fenômeno do movimento na analítica da existência? É precisamente no fim do $\$ 28$ de Ser e Tempo, quando Heidegger expóe que o existencial da decadência [Verfallen] envolve uma queda, um "cair" [fallen]. É justamente a queda, ressalta Heidegger, que “[...] mostra um modo existencial próprio de mobilidade" (HEIDEGGER, 2001, p. 180). Dessa maneira, o esclarecimento da decadência [Verfallen] como modo próprio de mobilidade existencial, depende da interpretaçấo deste "cair" 
[Fallen] que a caracteriza. Em que consiste esse "cair", essa queda existencial que constitui o ser-aí?

A mobilidade da decadência é necessariamente um acontecimento da própria existência, ou seja, não pode descrever uma ocorrência externa, como o cair desde uma posição espacial prévia superior, nem a perda de um estado de pureza originário, como seria padecer uma corrupção ontológica, nem muito menos significa um recair sobre algo que não seja a existência mesma. Se a existência tropeça na decadência, isso acontece, não porque tinha uma pedra no meio do caminho, mas, porque a existência se tornou um tropeço para si mesma: "O ser-aí enquanto decadente [verfallenes] já decaiu [abgefallen] de si mesmo como ser-no-mundo fático; e ele caiu não em algo entitativo, com o qual pudesse topar ou náo topar no transcurso do seu ser, mas no mundo, o mesmo que pertence ao seu ser" (HEIDEGGER, 2001, §38, p. 176).

A decadência é o modo de relação da existência com o seu mundo, na qual ela, através do envolvimento nos contextos de ocupação e pela coexistência com os outros, é absorvida, ou seja, tomada pelo mundo. $\mathrm{O}$ mundo, enquanto totalidade significativa sedimentada pela história e pela tradição, confere à existência o seu campo de possibilidades de ser, abrindo, com isso, o contexto em que a existência abandona o desafio da singularização, isto é, a tarefa de tornar-se si-mesma. A estrutura básica da decadência consiste, dessa forma, na tendência da existência em decair (abfallen) de si mesma no mundo, quer dizer, de deixar-se interpretar no horizonte do mundo no qual foi jogada e inserida.

Estas considerações, entretanto, não contribuem para determinação da mobilidade da existência enquanto não for possível apresentar no interior desta interpretação da relação da existência com o seu mundo a correlaçáo entre privação e fim que estrutura o movimento. Em que medida há uma privação na existência, a qual poderia de alguma maneira justificar o uso da noção de mobilidade para descrevê-la? De acordo com Heidegger, a concretização mais imediata da decadência é a perdição na publicidade do impessoal, no interior da qual cada um é como o outro e ninguém é si-mesmo. Apesar de se usar constantemente a palavra "eu", o eu cotidiano não é, de início e na maior parte das vezes, ele mesmo: "Inicialmente, eu não 'sou' um 'eu' no sentido no si-mesmo próprio. Ao contrário sou os outros no modo do impessoal" (HEIDEGGER, 2001, \$27, p. 129). Na cotidianidade mediana dominada pela interpretação vigente, tradicional, o si-mesmo existe de modo privativo, pois o "eu" cotidiano não é um si-mesmo próprio. A ausência privativa do eu não deve, evidentemente, ser interpretada em termos absolutos, como 
se aquele que vive o cotidiano estivesse desprovido de eu; a privação, como vimos em Aristóteles, não é apenas a negatividade da ausência que aponta para o que falta, mas também positividade, porque, para indicar a o que está ausente, a ausência ela mesma precisa apresentar-se. O "não-eu" cotidiano é um modo de ser do eu, nomeadamente aquele modo em que perde a si mesmo no redemoinho do mundo. Nessa ausência é que se pode anunciar a direção de uma recuperação possível para o ser-aí: "Na medida em que está perdido no impessoal, ele deve primeiro se encontrar. Para se encontrar, ele deve 'mostrarse’ em sua possível propriedade” (HEIDEGGER, 2001, \$54, p. 268).

Talvez esta aproximação entre a decadência e a privação aparente ser uma torção hermenêutica, ela possui, entretanto, base textual. De fato, logo no início do $\$ 40$ de Ser e Tempo, que trata da angústia, Heidegger observa, quase de passagem:

Existenciariamente na decadência a propriedade do ser-si-mesmo está fechada e obstruída; mas este fechamento é apenas a privação [Privation], que se revela fenomenalmente no fato, de que a fuga do ser-aí é fuga de si mesmo. É justamente daquilo que foge que o ser-aí corre atrás. Apenas porque o ser-aí é colocado ontologicamente por essência diante de si mesmo através de sua abertura, pode fugir de si mesmo. (HEIDEGGER, 2001, p. 184). ${ }^{5}$

Numa possível provocação contra a filosofia moderna, a qual descreve o ser humano como uma cápsula, preso e trancafiado na esfera subjetiva da interioridade, Heidegger afirma que a existência é abertura. A existência é aberta, na medida em que é compreensiva e disposta afetivamente, encontrando-se desde já diante de si mesma. Como a decadência consiste numa tentativa de escapar desse "estar-diante de si-mesmo", ela é um modo privativo de abertura (Erschlossenheit), em que a abertura se mostra no seu fechamento, demarcando a principal característica da privação, que é a de indicar o positivo através do negativo, evidenciando-se como presença da ausência. Como evidência clara de como o ser-aí nunca é um sujeito encapsulado em si mesmo, até o seu fechamento é um modo de abertura.

$\mathrm{Na}$ continuidade da aproximação com a descrição do movimento apresentada por Aristóteles, teríamos que definir a decadência como uma privação necessariamente através da relação com um telos, porque somente assim poderíamos utilizar a referência à privaçáo como estratégia hermenêutica

${ }^{5}$ Cf. também, HEIDEGGER, M. Zollikoner Seminare. Frankfurt am Main: Vittorio Klostermann, 2006, p. 94: "Fechamento se dá como privação apenas ali onde vigora a manifestação (Offenständigkeit)". 
para esclarecer o tipo especial de mobilidade existencial da decadência. Neste ponto, o paralelo náo se interrompe, contudo, exige uma alteração das correlaçôes conceituais. Se a noção de privação pressupóe a indicação de um contraponto positivo em comparação com o qual se pode falar de ausência, no caso da existência humana, não há referência a um telos que permita tal contraponto. A existência não é descrita na analítica existencial como um encaminhar-se para o término de uma trajetória que implique acabamento. A falta de telos é justamente o que impede que a aplicação do conceito de movimento seja apenas uma transposição, sem maiores mediaçóes, de um esquema conceitual aristotélico para a analítica existencial.

A fim de interpretar a decadência como a privação do ser si-mesmo próprio e compreender, por que "[...] a decadência é um conceito ontológico de movimento" (HEIDEGGER, 2001, $\$ 38$, p. 180), torna-se necessário relacioná-la com o fim específico da existência, que é a morte, pois esta, apesar de não ser o telos da existência, fornece efetivamente a chave hermenêutica para a compreensáo da mobilidade existencial no que diz respeito à perda ou apropriação de si. Como observa Heidegger, no relatório Natorp: "A tendência para queda [Verfallenstendenz] é o escapar de si mesma da vida. A manifestação mais aguda desta mobilidade fundamental é fornecida pela própria vida fática através do modo como posiciona-se frente a morte" (HEIDEGGER, 2005b, p. 358). O ser para a morte envolve uma referencialidade constitutiva da finitude ao seu próprio fim em relação com o qual será possível entender o caráter privativo da decadência. Na caracterização da morte enquanto fim [Ende], importa, sobretudo, descrevê-la como fenômeno existencial a ser concebido de acordo com o modo de ser do ser-aí, ou seja, resguardando seu caráter de possibilidade.

Em primeiro lugar, deve-se ressaltar que, se a finitude do ser-aí pressupóe uma referencialidade, ou seja, implica um ser para o fim, a morte não é interpretada como o ponto final de uma trajetória. Em outras palavras, o ser para o fim [Sein zum Ende] não significa o estar-no-fim [Zu-Ende-sein]. Heidegger diferencia claramente o falecimento [Ableben], enquanto evento de caráter biológico-fisiológico, do morrer [Sterben] enquanto modo de existir configurado a partir do poder-não-ser-mais-aí. De fato, há uma referencialidade no ser para a morte, mas se trata da referência existenciária à possibilidade da impossibilidade do ser-no-mundo. O que está em movimento no movimento existencial são modos de ser e atitudes, por isso, a mobilidade da decadência que foi caracterizada pela privaçáo tem que ser interpretada à luz da referência 
ao fim da existência enquanto posicionamento frente à morte que não seja encobridor de seu caráter de possibilidade.

Em segundo lugar, a morte como fim não pode ser compreendida por meio da noção de acabamento e completude. No $\$ 48$ de Ser e Tempo, Heidegger retoma um problema levantado no início da segunda seção da analítica existencial, o qual consiste na dificuldade em definir em que sentido seria possível conceber a existência como um todo, porque, sendo pura possibilidade de ser, estaria o existir aparentemente condenado a ser "[...] constante inconclusão” (HEIDEGGER, 2001, \$46, p. 236), a carregar consigo sempre possibilidades não realizadas, isto é, um "ainda-não" insuperável. A intenção última desse parágrafo é mostrar como essa dificuldade está assentada numa má compreensão do modo de ser do ser-aí, que o toma como um ente cujas possibilidades são pendências exteriores que o tornam incompleto. $\mathrm{O}$ não-ser da existência não é constituído por partes que faltam num somatório ou composição, todavia, por um não-ser que ela tem que ser.

Nesse contexto, Heidegger desenvolve um contraste que pode servir como contraponto com a concepção aristotélica. De fato, para esclarecer o fim da morte, o autor de Ser e Tempo compara o não-ser específico da existência com o não-ser próprio de um fruto imaturo em processo de maturação. À semelhança da existência, a maturidade, ou seja, o que o fruto se tornará, não é algo externo que se lhe acrescenta, já que mesmo imaturo ele já é o que se tornará. De maneira análoga, o "ainda-não" que caracteriza o ser-aí não é um conjunto de partes que lhe faltem, mas uma determinação constitutiva, ainda que negativa. A diferença fundamental é que, "[...] com o amadurecimento o fruto se completa [vollendet]” (HEIDEGGER, 2011, $\$ 48$, p. 244), enquanto a existência náo termina na completude conclusiva, porque mesmo a existência incompleta pode falecer. Nas palavras de Heidegger:

\footnotetext{
Na morte, o ser-aí nem se completa, nem simplesmente desaparece, nem se torna pronto ou disponível como à máo. Assim como o ser-aí, enquanto é, continuamente já é o seu ainda-não, assim também já é sempre o seu fim. O terminar implicado na morte não significa o ser e estar-no-fim do ser-aí, mas o seu ser-para-o-fim desse ente. A morte é um modo de ser, que o ser-aí assume, no momento em que é. "Para morrer basta está vivo". (HEIDEGGER, 2001, $\$ 48$, p. 245).
}

Sob dois ângulos, o conceito de telos revelou-se inadequado para a descrição do fim da existência. De um lado, não se trata de apontar para o 
término de um percurso, quer dizer, para o fim de um processo; de outro lado, não se trata também de indicar um estágio de plenitude ou acabamento almejado. Ora, se a morte náo é o ponto de chegada de um processo, nem acabamento, entáo de que modo podemos correlacionar a decadência como privação e o ser-para-morte como fim?

A morte adquire significado existencial como fim, quando deixa de ser encarada enquanto evento que ocorre no transcorrer de um processo para ser tomada enquanto possibilidade radical. Em outras palavras, o ser-para-o-fim envolve um contraponto para a privação da decadência somente na medida em que o "[...] não-ser extremo possui o caráter daquilo com que o ser-aí se comporta” (HEIDEGGER, 2001, $\$$ 50, p. 250). É nessa acepção que o fim poderá ser o eixo que articula a mobilidade da vida fática. A noção de "fim" pode ser interpretada existencialmente como sinônimo de meta ou alvo, quando é estabelecida pela decisão que antecipa a morte, assumindo a finitude. É evidente que a realização da possibilidade da morte não pode ser a meta constitutiva da existência, entretanto, o ser para o fim pode ser assumido sob a forma de uma escolha de si e ser considerado, nessa modalização, como meta. Por isso, a analítica existencial incorpora, ao seu modo, a máxima de Píndaro: "[...] tornate quem tu és” (HEIDEGGER, 2001, $\$ 31$, p. 145). Nas notas encontradas no exemplar de uso do autor, há o seguinte comentário a essa referência ao poeta grego: "Mas quem 'tu' és? Aquele como o qual tu te projetas a ti mesmo - aquele como tu te tornas" (HEIDEGGER, 2001, p. 443). A mobilidade da decadência se caracteriza por ser um impedimento dessa escolha de si, ao retirar da existência singular "[...] a possibilidade fática de que a vida tome a si mesma na preocupação [Bekümmerung] e, com isso, coloque como alvo [Ziel] o retorno apropriativo sobre si mesma” (HEIDEGGER, 2005b, p. 358).

Assim, evidencia-se que a estrutura básica do movimento descrita por Aristóteles retorna implicitamente através de várias mediaçóes na analítica existencial, numa tentativa de descrever a mobilidade da vida fática. $\mathrm{O}$ serpara-a-morte configura as possibilidades fundamentais de tornar-se um simesmo próprio, por meio da apropriaçáo de si ou permanecer um si-mesmo impróprio, percorrendo os caminhos trilhados pela tradição, perdido na publicidade do impessoal. Se a mobilidade da existência náo consiste num percurso que nos leva de um ponto de partida para um ponto de chegada, ela pode ser determinada como a oscilação entre dois modos de comportamento diante da possibilidade mais própria, irremissível, certa e, ao mesmo tempo, indeterminada e insuperável da morte. A mobilidade da existência revela-se 
pela possível alteração do modo de assunção do ser-para-o-fim; anuncia-se, entretanto, especialmente, na mudança que pode acontecer, ao modificarmos nosso ser-aí da privação de si-mesmo na decadência para a apropriação de simesmo escolhida como meta na decisão antecipadora. Pode-se acompanhar o paralelo entre a estrutura do movimento apresentada por Aristóteles e a própria articulação de Ser e Tempo.

A primeira seção da obra descreve a cotidianidade mediana marcada pela tendência constitutiva da existência de fugir de si mesma, comportandose com relação ao seu fim sob a forma do encobrimento, e constituindo, através do desvio, da esquiva, da retirada, ou seja, da privaçáo de si-mesmo na perdição do impessoal. Se o cotidiano decadente não é o ponto de partida de uma trajetória que inevitavelmente será percorrida, é, certamente, o modo de existir no qual "de início e na maior parte das vezes" o ser-aí se encontra a si mesmo. Na cotidianidade mediana, temos a mobilidade da decadência, porque, de início, não sou propriamente eu-mesmo, sou impropriamente como os outros, sou privação de mim decaindo no mundo. A segunda seçáo da obra descreve as diferentes condições para uma existência própria, através de análises da morte, da voz da consciência e da decisão. Essas análises visam a evidenciar que o poder-ser próprio não é uma construção abstrata ou mero ideal de vida; objetivam mostrar que há base fenomenal para a propriedade. Isso atesta que a existência, sendo tarefa de ser, não permanece definitivamente imersa na privação de si, pois pode encontrar caminhos para aceitação da finitude e assumi-los pela decisão. $\mathrm{O}$ fechamento da decadência não é originário, porque pressupóe a abertura; a privação aponta implicitamente para a meta da assunção de si. $\mathrm{Na}$ apropriação de si, o ser-aí torna-se quem é, conquista a verdade da existência, ao ser de fato um mortal: "Somente o ser-livre para a morte concede ao ser-aí o fim sem mais [Ziel schlechthin], colocando a existência na sua finitude" (HEIDEGGER, 2001, $\$ 74$, p. 384)

A centralidade da análise do movimento pode ser percebida pela referência à estrutura fundamental da existência. A relevância se torna mais clara, quando suas consequências são ressaltadas, especialmente a que concerne à filosofia enquanto tal. $\mathrm{O}$ esclarecimento mais aprofundado da mobilidade da existência, sobretudo a que se evidencia na transformação existenciária que permeia a modificação da impropriedade para a impropriedade, fortalece o entendimento do que Heidegger denomina, não por acaso, movimento 
primordial [Urbewegung] $]^{6}$ a transcendência do ser-aí. As mobilidades, acima analisadas, da privação de si, na decadência, e apropriação de si, na decisão antecipadora, são modalizaçôes do movimento originário da existência, o acontecer temporal da transcendência.

A noção de mobilidade existencial possui, pela relação direta com as modalidades própria e imprópria de autorrelação, uma função metódica clara. Não é difícil perceber que a análise da decadência se conecta com um velho problema que reaparece sob diferentes entonaçóes na história da filosofia. Refiro-me à problemática relação entre os polos episteme e doxa, teoria e práxis, senso comum e saber científico, reflexão filosófica e vida cotidiana, ou, em termos husserlianos, entre a atitude natural e a atitude fenomenológica.

A própria filosofia revela-se, portanto, como expressão possível da mobilidade da existência, nas suas oscilaçóes entre ser ou não ser propriamente si mesma. Se o ser-aí na sua existência cotidiana é determinado existencialmente pela mobilidade fundamental da decadência, que implica o decair na reprodução da tradição, no assumir imediato de uma interpretação vigente, entâo o filosofar somente pode acontecer através de um contramovimento [Gegenbewegung] contra a tendência à decadência ${ }^{7}$.

AQUINO, Thiago. The Fallenness of Existence: notes on the mobility of life. Trans/Form/ Ação, Marília, v. 38, n. 2, p. 35-52, Maio/Ago., 2015.

ABSTRACT: This article discusses the philosophical concept of movement in an attempt to demonstrate how broadening its scope is relevant for a phenomenological understanding of human existence. I intend to offer an interpretation of Heidegger's idea, presented on Being and Time, that the phenomena of existential fallenness (Verfallen) is an ontological concept of existential mobility.

KEYWORDS: Heidegger. movement. deprivation. ontology. self.

${ }^{6}$ HEIDEGGER, M.; Vom Wesen des Grundes. In: Wegmarken, OC 9, Frankfurt am Main: Vittorio Klostermann, 2004, p. 174.

${ }^{7}$ HEIDEGGER. Phänomenologische Interpretation zu Aristoteles. (Anzeige der hermeneutischen Situation), OC 67, p. 361. 


\section{REFERÊNCIAS}

ARISTOTLE. Physics. In: BARNES, Jonathan (ed.). The Complete works of Aristotle. Princeton, NJ: Princeton University Press, 1984a. p. 315-446.

Metaphysic. In: BARNES, Jonathan (ed.). The Complete works of Aristotle. Princeton, NJ: Princeton University Press, 1984b. p. 1552-1728.

ÉVORA, F. R. Physis, Kinesis, Topos e Kenon: um estudo da teoria aristotélica do movimento. Cadernos de Estudos Espinosanos, São Paulo, v. 8, p. 52-74, 2002.

HEIDEGGER, Martin. Ser e tempo I-II. Tradução de Márcia de Sá Calvacanti. Petrópolis: Vozes, 1998.

. Sein und Zeit. Tübingen: Max Niemeyer, 2001.

. Wegmarken, OC 9. Frankfurt am Main: Vittorio Klostermann, $2004 a$.

. Vom Wesen des Grundes. In: . Wegmarken, OC 9. Frankfurt am Main:

Vittorio Klostermann, 2004b.

Phänomenologische Interpretationen ausgewählter Abhandlungen des Aristoteles zur Ontologie und Logik, OC 67. Frankfurt am Main: Vittorio Klostermann, 2005a.

. Phänomenologische Interpretationen zu Aristoteles (Anzeige der hermeneutischen Situation). In: . Phänomenologische Interpretationen ausgewählter Abhandlungen des Aristoteles zur Ontologie und Logik, OC 67. Frankfurt am Main: Vittorio Klostermann, 2005b. p. 340-399.

. Zollikoner Seminare. Frankfurt am Main: Vittorio Klostermann, 2006.

. Marcas do caminho. Tradução de Enio Paulo Giachini e Ernildo Stein. Petrópolis: Vozes, 2008.

. A Essência do fundamento. In: Marcas do caminho. Petrópolis: Vozes, 2008.

Recebido / Received: 08/02/2015

Aprovado / Approved: 10/03/2015 